\title{
SUPPLEMENT TO A PAPER
}

on

\section{FIBR0-CALCAREOUS TUMOURS,}

AND

\section{POLYPI OF THE UTERUS.}

PUBLISHED IN VOLUME XIX OF THE MEDICO-CHIRURGICAL TRANSACTIONS.

BY

ROBERT LEE, MD. F.R.S.

FELLOW OF THE ROYAL COLLEGE OF PHYSICIANS, PHYSICIAN TO THE BRITISH LYING-IN-HOSPITAL, PHYSICIAN-ACCOUCHEUR TO THE ST. MARY-LE-BONE INFIRMARY, LECTURER ON MIDWIFERY AND THE DISEASES OF WOMEN AND CHILDREN AT ST. GEORGE'S HOSPITAL.

Received April 30th.-Read May 28th, 1850.

IN a paper, published in the Nineteenth volume of the Medico-Chirurgical Transactions, I have stated, that when large, " the fibrous tumour of the uterus is often unequal on its surface, being lobulated or divided by deep fissures and arteries, and veins of considerable magnitude can be traced into its substance." Before the publication of this paper, it had been observed by Sir Charles Clarke, that "if coloured injection be thrown into the vessels of the uterus, so as to make the substance of the uterus quite red, none of it passes to the tumour of fleshy tubercle. In the collection of $\mathrm{Mr}$. Abernethy, surgeon to St. Bartholomew's Hospital, there is a very good preparation showing this fact."' Very recently an author, who is said to have carefully investigated the structure of fibrous tumours of the uterus, states, that " the veins, although closely collected around the growth, do not appear to enter it." And another still more recent writer asserts, that "no veins are observed in the structure of these

' Observations on the Diseases of Females, \&c., p. 269. By Charles Mansfield Clarke.-London, 1821. 
tumours : they only appear to be collected on their surface where they are large and varicose."1

In the Museum of St. George's Hospital, there are various specimens of fibrous tumours of the uterus, in which both the arteries and veins have been injected. From these it is seen, that when the arteries reach the tumour, they do not at once plunge into its substance, but pass into the fissures or grooves on the outer surface of the membrane forming the sheath; and as the arteries run along these fissures between the lobes, small branches are given off to the surrounding parts. Veins of very considerable size are seen passing from the central parts of these tumours to their surface in a winding manner, and gradually enlarging till they terminate in the uterine veins. In these preparations, the veins of fibrous tumours have been filled with injection, thrown into branches ramifying throughout the substance of the tumours, and also from trunks of the uterine veins. I have repeatedly met with coagula of blood, which extended from the uterine veins into the veins of fibrous tumours, by which the continuity of these vessels could be demonstrated, and the course of the circulation of the blood through such tumours clearly determined.

In the same paper I have likewise observed, that " cavities containing a bloody or dark coloured gelatinous fluid are sometimes formed in the central part of the tumour, probably by a process of softening which its substance undergoes." At St. George's Hospital, a few years ago, Mr. Prescott Hewett showed me a specimen of this tumour weighing fifty-four pounds, in the central parts of which there were several large cavities filled with viscid fluid, which had led to the supposition during the life of the patient from whose body it had been removed, that the tumour was ovarian, and indeed even after death it was sent to London as a specimen of disease of the ovary, and the mistake was only discovered when a careful examination of the ovaria was made, and they were both found in a healthy condition. More than twenty years ago

${ }^{1}$ On Tumours of the Uterus, \&c., p. 9. By T. Stafford Lee.-London, 1847. 
I saw a tumour nearly similar in size and structure, which had been removed during life, by an extensive incision through the abdominal parietes, on the supposition that it was an ovarian cyst. The operation of tapping has been performed in a few cases of the same disease, but in none of these did the fluid in the cavities of fibrous tumours result from inflammation and suppuration.

It has been stated by several recent writers, that fibrous tumours of the uterus inflame and suppurate; but until the occurrence of the following remarkable case of abscess in the centre of a fibrous tumour imbedded in the walls of the uterus, I had never seen an example of this morbid alteration of structure, nor met with any pathologist who had witnessed the phenomenon. If the fact has ever before been observed, I am not aware that it has been distinctly demonstrated, or its importance pointed out in the diagnosis and treatment of the disease.

Mrs. S — , aged 40 years, married, but never pregnant, came under my care in 1843, when I inferred, from the enlarged and hard state of the body of the uterus, shortening of the cervix, attacks of menorrhagia, and other symptoms, that one or more fibrous tumours existed in the walls of the organ. From that period till the close of 1849 , I had frequent opportunities of seeing this patient, and of ascertaining by examination, that the uterus had not increased much in size during the six years that I had watched the progress of the disease.

About the middle of March, 1850, Mrs. S - was induced to consult another practitioner. She has stated, that six round masses called balls, were prescribed by him for her, one of which she was directed to introduce into the vagina every night at bedtime. After four of these balls had been used, so much tenderness of the parts supervened, that their further use was discontinued. The pain having increased, the same practitioner was requested to visit the patient, and at this interview, according to the report of the patient's sister, he passed an instrument within the parts. At the 
time this operation was performed, little or no pain was felt, but soon after acute suffering was experienced in the region of the uterus, and incessant vomiting with fever succeeded. The symptoms having assumed an alarming character, I was requested to see Mrs. S - on the 15th of April. The pain and vomiting partially ceased after the application of leeches, and other remedies, but the inflammation of the uterus was not arrested, and death took place on the morning of the 18th. The day after, the body was examined by Mr. Wharton Jones and myself. The uterus was about the size of a cricket ball, and hard. The ovaria and fallopian tubes on both sides, and the uterus and rectum, adhered together by old false membranes. Having removed the uterus from the body, an incision was made through its anterior wall, when there flowed out a quantity of greenish yellow fœtid pus. This matter had escaped from an irregular cavity in the centre of a fibrous tumour, which still contained a portion of purulent fluid. The whole lining membrane of the uterus was red and inflamed, and near the cervix appeared softened and disorganized. The anterior lip of the os uteri was of a peculiarly livid colour. The sac of the peritoneum presented no trace of recent inflammation. The cavity in the fibrous tumour from which the pus had escaped is seen in the preparation of the parts, and which is preserved in the Museum of St. George's Hospital. 